\title{
Structural and Optical Properties of Sol-gel Prepared ZnO Thin Film
}

\author{
Nanda Shakti (Corresponding author) \\ Department of Applied Physics, Indian School of Mines \\ Dhanbad -826004, India \\ E-mail: nash_cbsa@yahoo.co.in \\ P.S.Gupta \\ Department of Applied Physics, Indian School of Mines \\ Dhanbad -826004, India \\ E-mail: psgupta2ism@yahoo.co.in
}

\begin{abstract}
In this work we have studied the structural and optical properties of $\mathrm{ZnO}$ thin films prepared by sol-gel spin coating process. Zinc acetate dihydrate was used as the precursor material. Thin films of $\mathrm{ZnO}$ were prepared on Quartz substrate post annealed at $400^{\circ} \mathrm{C}, 500^{\circ} \mathrm{C}$ and $600^{\circ} \mathrm{C}$. X-ray diffraction (XRD) of the films showed polycrystalline nature. Scherrer's formula was used to calculate crystallite size. Scanning electron microscopy (SEM) study showed granular surface. The refractive index, extinction coefficient and thickness of the films were measured with spectroscopic Ellipsometry. The band gap and Urbach energy were calculated. The photoluminescence measurement revealed UV emission at $\sim 380 \mathrm{~nm}$.
\end{abstract}

Keywords: Sol-gel, XRD, SEM, Ellipsometry, Band gap

\section{Introduction}

Zinc oxide is an inexpensive n-type semiconductor having direct band gap of $3.3 \mathrm{eV}$ which crystallizes in hexagonal Wurtzite structure $(c=5.025$ and $\mathrm{a}=3.249)$ (Chennupati Jagadish and Stephen J.Pearton, 2007). Due to large exciton binding energy of $60 \mathrm{meV}$, they have potential applications in Optoelectronic devices such as in solar cells(Fortunato E. et al.,2004), Optical wave guide(Yu P. et al.,1998), Light emitting diodes (LED) (Tsukazaki A. et al,2005). Zinc oxide thin films are applied in Thin Film Transistors (TFT) (Ohya Y. et al., 2001) and have been recognized as Spintronic material (Sharma Parmanand et al.,2004).Various gas, chemical and biological sensors were based on $\mathrm{ZnO}$ thin film(Kang W.P.and Kim C.K.,1993). Thin films of Zinc oxide can be prepared by various techniques; among them are Sputtering (Moustaghfir A. et al.,2003), Chemical Vapor Deposition (CVD)(Haga K. et al.,2000), Laser ablation(Narasimhan K.L. et al., 1997), Sol-gel(Dinguha Bao et al.,1998), Spray pyrolysis(Paraguay F.D. et al.,1999). M. Inoguchi et al. (2009) have studied structural \& optical properties of nanocrystalline $\mathrm{ZnO}$ thin films derived from clear emulsion of monodispersed $\mathrm{ZnO}$ nanocrystals.

Properties of $\mathrm{ZnO}$ thin films show dependence on the technique used. Apart from doping, to increase the functionality of $\mathrm{ZnO}$ thin film, the effect of preparation conditions on the properties have to be considered for its effective technological applications. Relatively few works (Pramod Sagar et al., 2007; Harish Bahadur et al., 2006) have been done in this direction for $\mathrm{ZnO}$ film prepared by sol-gel process. In the present work we have used sol-gel spin coating process (C.Jeffry Brinker and George W. Scherer, 1990) for film preparation. Zinc acetate dihydrate was used as the precursor material. The Sol-gel process has the advantages of controllability of compositions, simplicity in processing and is cost effective. We have studied the effect of annealing the $\mathrm{ZnO}$ thin film at three different temperatures $\left(400^{\circ} \mathrm{C}, 500^{\circ} \mathrm{C}\right.$ and $\left.600^{\circ} \mathrm{C}\right)$ on its structural and optical properties. X-ray diffraction (XRD) and Scanning electron microscopy (SEM) were used for structural characterization. UV-VIS-NIR spectrometry, Photoluminescence and spectroscopic Ellipsometry were used for optical characterization.

\section{Experimental details}

$\mathrm{ZnO}$ thin films were prepared on fused Quartz substrates $\left(2.5 \times 2.5 \mathrm{Cm}^{2}\right)$ by sol-gel spin coating method. The Quartz substrates were cleaned with soap solution followed by ultrasonication in acetone for 5 min. Then it was 
degreased in ethanol for final cleaning. For sol preparation $10 \%$ solution of Zinc acetate dihydrate [ $\mathrm{Zn}$ $\left.\left(\mathrm{CH}_{3} \mathrm{COO}\right)_{2}\right] .2 \mathrm{H}_{2} \mathrm{O}$ was prepared in boiling iso-proponal. The turbid solution was cleared by adding 10 drops of diethanolamine by a $5 \mathrm{ml}$ dropper. The clear sol was further boiled for $30 \mathrm{~min}$. The sol was then allowed to cool to room temperature. For film preparation, the Quartz substrate was spin coated by a spin coater (SCU 2005 Apex Inst.Co.) while spinning rate was kept at $3000 \mathrm{rpm}$. The wet films were dried at $100^{\circ} \mathrm{C}$ for $10 \mathrm{~min}$ and subsequent annealed for $1 \mathrm{hr}$. The process was repeated to obtain the workable thickness of the film. Multilayer films post annealed at $400^{\circ} \mathrm{C}, 500^{\circ} \mathrm{C}$ and $600^{\circ} \mathrm{C}$ for $1 \mathrm{hr}$ were prepared to study the effect of annealing.

The structural properties of the prepared films were studied by X-ray diffraction measurements (Panalytical Xpert pro, with CuK $\alpha$ radiation $(\lambda=1.54059 \AA)$ ). Scanning electron microscope (Jeol; JSM-6390LV) was used to record Energy dispersive scattering (EDS) and surface morphology.

UV-VIS-NIR Spectrophotometer (HR 4000 Ocean Optics) was used to record the transmission spectrum of the films in the wavelength range from $250 \mathrm{~nm}$ to $600 \mathrm{~nm}$.Ellipsometer (Nano View; SE MG-1000UV) was used to measure refractive index $\mathrm{n}$, extinction coefficient $\mathrm{k}$ and thickness of the films. Photoluminescence of the films was measured by Spectroflurophotometer (Hitachi).

\section{Results and discussion}

\subsection{Structural properties}

The crystal structure of $\mathrm{ZnO}$ films was investigated through X-ray diffraction (XRD). The X-ray diffraction spectrum of $\mathrm{ZnO}$ film annealed at $400^{\circ} \mathrm{C}, 500^{\circ} \mathrm{C}$ and $600^{\circ} \mathrm{C}$ with prominent reflection planes is shown in figure 1.The peaks in the XRD spectrum correspond to those of the ZnO patterns from the JCPDS data (Powder Diffraction File, Card no: $36-1451$ ), having hexagonal wurtzite structure with lattice constants a=3.24982 $\AA$, $\mathrm{c}=5.20661 \AA$. The presence of prominent peaks shows that the film is polycrystalline in nature. The lattice constants ' $a$ ' and ' $c$ ' of the Wurtzite structure of $\mathrm{ZnO}$ can be calculated using the relations (1) \& (2) given below (C.Suryanarayana, and M.Grant Norton, 1998).

$$
\begin{aligned}
& \mathrm{a}=\sqrt{\frac{1}{3}} \frac{\lambda}{\sin \theta} \\
& \mathrm{c}=\frac{\lambda}{\sin \theta}
\end{aligned}
$$

For (002) plane calculated values are $\mathrm{a}=3.15$ and $\mathrm{c}=5.29$ which agrees with the JCPDS data. The full width at half maximum for (100),(002) and (101) planes as a function of annealing temperature is shown in figure 2 .

The crystallite size of the $\mathrm{ZnO}$ films annealed at different temperatures was calculated by using Scherrer's formula (B.D.Cullity and S.R. Stock, 2001).

$$
D=\frac{0.9 \lambda}{\beta \cos \theta}
$$

Where $D$ is the crystallite size, wavelength of the X-ray used is $\lambda=1.54059 \AA, \beta$ is the broadening of diffraction line measured at the half of its maximum intensity in radians and $\theta$ is the angle of diffraction. Table 1 gives the crystallite size along prominent diffraction planes for films annealed at different annealing temperatures. From the table we observe that for (002) plane the crystallite size suddenly increases at $500^{\circ} \mathrm{C}$ and again reduced to the same value with increase in annealing temperature. This may be due to the fact that on heat treatment, the flow of fluid near the substrate interface coagulates, to reorganize the grain size to increase. The coagulation process discontinues on further increasing the heat treatment temperature with threshold around $500^{\circ} \mathrm{C}$ (Gosh T. et al.2009).

The micro structural analysis of the $\mathrm{ZnO}$ film annealed at $400^{\circ} \mathrm{C}$ was carried out using Scanning electron microscope (SEM) with energy dispersive scattering (EDS) attachment. Figure3 shows the surface morphology of the $\mathrm{ZnO}$ film annealed at $400^{\circ} \mathrm{C}$. The film surface is granular in nature with grain size of the order of $\mathrm{nm}$. The EDS analysis of the film (Fig.4) shows the presence of Zinc, Oxygen, Silicon and Gold. The Gold in the ZnO film is from the Gold coating of the sample $\mathrm{ZnO}$ film for SEM analysis. 


\subsection{Optical properties}

Figure 5 shows the transmission spectra of the $\mathrm{ZnO}$ films deposited at different annealing temperatures. The spectra show interference fringes which has its origin in the interference of light reflected between air-film and film-substrate interface. The appearance of interference fringes indicates smooth reflecting surface of the film and low scattering loss at the surface. The films annealed at $400^{\circ} \mathrm{C}$ and $600^{\circ} \mathrm{C}$ exhibit good transparency in visible region $(>90 \%)$.

From the spectrometric Ellipsometry, the thicknesses of the $\mathrm{ZnO}$ films annealed at $400^{\circ} \mathrm{C}, 500^{\circ} \mathrm{C}$ and $600^{\circ} \mathrm{C}$ are measured to be $120.4 \mathrm{~nm}, 163.3 \mathrm{~nm}$ and $64.7 \mathrm{~nm}$ respectively. The variation of refractive index $\mathrm{n}$ and extinction coefficient $\mathrm{k}$ with photon energy for $\mathrm{ZnO}$ films annealed at different temperatures is shown in figure 6 and 7 .In figure 6 the refractive index increases with increasing photon energy, with peak at about $3.25 \mathrm{eV}$. This can be attributed to the band gap of $\mathrm{ZnO} \sim 3.3 \mathrm{eV}$.It may be noted that the refractive index $\mathrm{n}$ is almost unaffected by the variation in the annealing temperature upto the peak, that is, $3.25 \mathrm{eV}$, after which it shows a small dependence on the annealing temperature. Figure 7 shows $\mathrm{k}$ to build up only after $3 \mathrm{eV}$ and attains a peak at $3.4 \mathrm{eV}$. It also shows a dependence on annealing temperature above $3 \mathrm{eV}$.

The absorption coefficient $\alpha$ and the extinction coefficient $k$ are related by the formula (Shaaban E.R., 2006)

$$
\mathrm{k}=\frac{\alpha \lambda}{4 \pi}
$$

The Optical energy gap $\mathrm{E}_{\mathrm{g}}$ and absorption coefficient $\alpha$ are related by the equation

$$
\alpha=\left(\frac{k}{h v}\right)\left(h v-E_{g}\right)^{\beta}
$$

where $\mathrm{k}=\mathrm{a}$ constant

$$
\mathrm{h}=\text { Planck's constant }
$$

$\mathrm{h} v=$ The incident photon energy and $\beta$ is a number which characterizes the nature of electronic transition between valance band and conduction band (Ming-Fu Li, 2001). For direct allowed transitions $\beta=1 / 2$ and it is known that $\mathrm{ZnO}$ is a direct bandgap semiconductor. Therefore the formula used is

which gives

$$
\begin{gathered}
\alpha=\left(\frac{k}{h v}\right)\left(h v-E_{g}\right)^{1 / 2} \\
(h v \alpha)^{2}=C\left(h v-E_{g}\right)
\end{gathered}
$$

where $\mathrm{C}$ is a constant. The variation of $(\mathrm{h} v \alpha)^{2}$ vs. $\mathrm{h} v$ as obtained using equation (6) is shown in Fig. 8 for $\mathrm{ZnO}$ films annealed at different temperatures.

The energy gap $\mathrm{E}_{\mathrm{g}}$ of the samples was evaluated from the intercept of the linear portion of the each curve for different annealing temperature with the $\mathrm{h} v$ in $\mathrm{X}$-axis. Table 2 gives values of $\mathrm{E}_{\mathrm{g}}$ of the films deposited at different annealing temperatures.

The value of Band gap as calculated above agrees nearly with band gap of bulk $\mathrm{ZnO}(3.37 \mathrm{eV})$.

It is assumed that the absorption coefficient $\alpha$ near the band edge shows an exponential dependence on photon energy for many materials. This dependence is given by (Urbach F., 1953)

$$
\alpha=\alpha_{0} \exp \left(\frac{h v}{E_{u}}\right)
$$


where $\alpha_{o}$ is a constant and $E_{u}$ is Urbach energy which is the width of the tails of the localized state associated with the amorphous state in the forbidden band. The plot of $\ln \alpha$ vs. photon energy hv plots for $\mathrm{ZnO}$ thin films annealed at $400^{\circ} \mathrm{C}, 500^{\circ} \mathrm{C}$ and $600^{\circ} \mathrm{C}$ is shown in figure 9 .

From the plot the value of Urbach energy at the band edge $\sim 3.21 \mathrm{eV}$ for films annealed at different temperatures is shown in table 3. From the table, the increase in Urbach energy between $400^{\circ} \mathrm{C}$ and $500^{\circ} \mathrm{C}$ may be attributed to the increase thermal induced structural disorder of the film within this temperature range (Xue S.W.,et al. 2006).

The room temperature Photoluminescence (PL) of $\mathrm{ZnO}$ film annealed at different temperatures is shown in figure 10.At the excitation wavelength of $315 \mathrm{~nm}$ the PL spectrum consist of a prominent peak at about $380 \mathrm{~nm}$ responsible for UV emission and suppressed peak at about $500 \mathrm{~nm}$ responsible for green emission. The reason of negligible intensity at $500 \mathrm{~nm}$ may lie in the fact that with increasing annealing temperature, both the amount of grown $\mathrm{ZnO}$ and the specific surface area of the grains decreases, which jointly weakens the green emission. The band $\sim 380 \mathrm{~nm}$ correspond to the band edge emission due to free exciton while at $\sim 500 \mathrm{~nm}$ attributed to the presence of defects, non stoichiometry and crystal imperfection (Pramod Sagar et al., 2007). From the spectra we note UV emission depends on the annealing temperature. This type of variation can be attributed to the polycrystalline nature of $\mathrm{ZnO}$ film.

\section{Conclusions}

$\mathrm{ZnO}$ thin films prepared on Quartz substrate by sol-gel spin coating process with post annealing temperatures at $400^{\circ} \mathrm{C}, 500^{\circ} \mathrm{C}$ and $600^{\circ} \mathrm{C}$. The structural characterization of the film was done by X-Ray Diffraction (XRD). From XRD spectrum of the film the characteristic reflection planes of $\mathrm{ZnO}$ was verified. The lattice constants were calculated, which agreed with that of bulk ZnO. Crystallite size of the films was found to be less than 100 $\mathrm{m}$. The transmission spectrums of the films were recorded by UV-VIS-NIR Spectrophotometer. The films showed high transparency $(>90 \%)$ in the visible region .The refractive indices, extinction coefficients, thicknesses were measured with Ellipsometer. The refractive index and extinction coefficient showed some variation with rise in annealing temperature of $\mathrm{ZnO}$ film. The Optical energy band gaps gave value of 3.21 eV.The Urbach energy of the $\mathrm{ZnO}$ films were $\sim 100 \mathrm{meV}$. The value of band gaps agrees approximately with that of bulk $\mathrm{ZnO}$.The photoluminescence spectra of $\mathrm{ZnO}$ films showed prominent $\mathrm{UV}$ emission $(\sim 380 \mathrm{~nm})$ and suppressed green emission $(\sim 500 \mathrm{~nm})$. The temperature range will be increased in our future work for more generic applications.

\section{References}

Bahadur, Harish, Samanta, S.B., Srivastava, A.K., Sood, K.N, Kishore, R., Sharma, R.K., Basu,A., M.Kar, Rashmi, Pal, Prem, Bhatt, Vivekanand, \& Chandra, Sudhir. (2006). Nanostructured ZnO films by sol-gel process. Material Science, 41, 7562.

Bao, Dinguha, Gu, Haoshuang, \& Kuang, Anxiang. (1998). Sol-gel derived c-axis oriented ZnO thin films. Thin Solid Films, 132, 37-39.

Brinker C.Jeffry \& Scherer, George W. (1990). Sol-gel Science the Physics and Chemistry of sol-gel processing, San Diego: Academic Press (Chapter 2).

Cullity B.D. \& Stock, S.R. (2001). Elements of X-Ray diffraction ( $3^{\text {rd }}$ ed.), Prentice Hall.

Fortunato, E., Goncalves, A., Marques, A., Viana, A., Aguas, H., Pereira, L., Ferreira, I.,Vilarinho, P., \& Martins, R. (2004). New developments in gallium doped Zinc oxide deposited on polymeric substrates by RF magnetron sputtering. Surface and Coatings Technology, 180, 20-25.

Ghosh T., Bandopadhyay S., Roy K.K., Maiti A.K. \& Goswami, K. (2009). Optical studies on ZnO films prepared by sol-gel method. Crystal Research and Technology, 44,879-882.

Haga, K., Kamidaira, M., Kashiwaba, Y., Sekiguchi, T., \& Watanabe, H. (2000). ZnO thin films prepared by remote plasma-enhanced CVD method. Journal of Crystal Growth, 214, 77-80.

Inoguchi, M., Suzuki, K., Tanaka, N., Kageyama, K., \& Takagi, H. (2009). Structural and optical properties of nanocrystalline $\mathrm{ZnO}$ thin films derived from clear emulsion of monodispersed $\mathrm{ZnO}$ nanocrystals. Journal of Materials Research, 24, 2243-2251.

Jagadish, Chennupati \& Pearton, Stephen J. (2007). Zinc oxide Bulk, Thin Films and Nanostructures, China: Elsevier .

Joint Committee on Powder Diffraction Standards, Powder Diffraction File, Card no: 36-1451. 
Kang, W.P., \&Kim, C.K. (1993). Catalyst-adsorptive Oxide-semiconductor gas sensors. Sensors and Actuators: B, 14,682-684.

Li, Ming-Fu. (2001). Modern Semiconductor Quantum Physics, Singapore: World Scientific.

Moustaghfir, A., Tomasella, E., Amor, S.Ben, Jcquet, M., Cellier, J., \& Sauvage, T. (2003). Structural and Optical studies of $\mathrm{ZnO}$ thin films deposited by r.f. magnetron sputtering: influence of annealing. Surface and Coatings Technology, 174-175,193-196.

Narasimhan, K.L., Pai, S.P., Palkar V.R., \& Pinto R. (1997). High quality Zinc Oxide films by pulsed laser ablation. Thin Solid Films, 295, 104-106.

Ohya, Y., Niwa, T., Ban, T., \& Takahashi, Y. (2001). Thin Film Transistor of ZnO Fabricated by Chemical solution Deposition. Japanese Journal of Applied Physics, 40,297-298.

Paraguay, F.D., Estrada, W.L., Acosta, D.R.N., Andrade E., \& Mikiyoshida, M. (1999). Growth structure and optical characterisation of high quality $\mathrm{ZnO}$ thin films obtained by spray pyrolysis. Thin Solid Films, 350, 192-202.

Sagar, Pramod, Shishodia, P.K., Mehra, R.M., Okada, H., Wakahara, Akihiro, \& Yoshida, Akira. (2007). Photoluminescence and absorption in sol-gel derived ZnO films. Journal of Luminesence, 126,800-806.

Shaaban, E.R. (2006). Calculation of the optical constants of amorphous semiconducting $\mathrm{As}_{40} \mathrm{~S}_{60}, \mathrm{As}_{40} \mathrm{~S}_{25} \mathrm{Se}_{25}$ and $\mathrm{As}_{40} \mathrm{Se}_{60}$ Thin films from transmittance and reflectance measurements. Journal of Applied Sciences, 6(2), 340-346.

Sharma, Parmanand, Gupta, Amita, Owens, J.Frank, Inoue, Akhisha, \& Rao K.V. (2004). Room temperature Spintronic material-Mn-doped $\mathrm{ZnO}$ revisited. Journal of Magnetism and Magnetic materials, 282, 115-121.

Suryanarayana, C., \& Norton, M. Grant. (1998). X-Ray Diffraction A practical approach, New York: Plenum Press (1998).

Tsukazaki, A., Kubota, M., Ohtomo, A., Onuma, T., Ohtani, K., Ohno, H., Chichibu, S.F., \& Kawasaki, M. (2005).Blue light-Emitting Diode based on ZnO. Japanese Journal of Applied Physics, 44, L643-L645.

Urbach, F. (1953). The long-wavelength edge of the photographic sensitivity and of the electronic absorption of solids. Physical Review, 92, 1324-1324

Xue, S.W., Zu, X.T., Zhou, W.L., Deng, H.X., Xiang, X., Zhang L. \& Deng H. (2008). Effects of post-thermal annealing on the optical constants of $\mathrm{ZnO}$ thin films. Journal of Alloys and Compounds, 448, 21-26.

Yu, P., Tang, Z.K., Wong, G.K.L., Kawasaki, M., Ohtomo, A., Koinuma, H. \&Segawa, Y. (1998). Room -temperature gain spectra and lasing in microcrystalline $\mathrm{ZnO}$ thin films. Journal of Crystal growth, 184-185, 601-604.

Table 1. Crystallite size along prominent diffraction planes for $\mathrm{ZnO}$ films annealed at $400^{\circ} \mathrm{C}, 500^{\circ} \mathrm{C}$ and $600^{\circ} \mathrm{C}$

\begin{tabular}{|c|c|c|c|}
\hline \multirow{2}{*}{$\begin{array}{c}\text { Annealing } \\
\text { temperature } \\
\left({ }^{\circ} \mathrm{C}\right)\end{array}$} & \multicolumn{3}{|c|}{ Crystallite Size (in nm) along diffraction planes } \\
\cline { 2 - 4 } & $(100)$ & $(002)$ & $(101)$ \\
\hline 400 & 46 & 38 & 34 \\
\hline 500 & 46 & 67 & 45 \\
\hline 600 & 53 & 38 & 54 \\
\hline
\end{tabular}


Table 2. Band gap Eg for $\mathrm{ZnO}$ films at different annealing temperature as estimated from Fig.8

\begin{tabular}{|c|c|}
\hline $\begin{array}{c}\text { Annealing } \\
\text { temperature }\left({ }^{\circ} \mathrm{C}\right)\end{array}$ & Band gap $\mathrm{E}_{\mathrm{g}}(\mathrm{eV})$ \\
\hline 400 & 3.216 \\
\hline 500 & 3.212 \\
\hline 600 & 3.216 \\
\hline
\end{tabular}

Table 3. Urbach energy for $\mathrm{ZnO}$ thin films annealed at different temperatures

\begin{tabular}{|c|c|}
\hline Annealing temperature $\left({ }^{\circ} \mathrm{C}\right)$ & Urbach energy $E_{u}(\mathrm{~m} \mathrm{eV})$ \\
\hline 400 & 96.6 \\
\hline 500 & 101.0 \\
\hline 600 & 101.0 \\
\hline
\end{tabular}

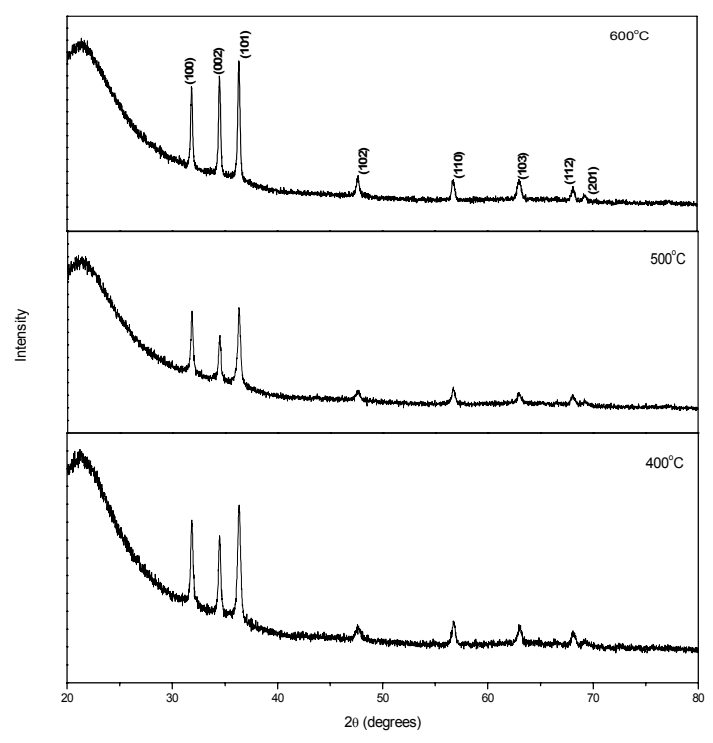

Figure 1. XRD spectrum of $\mathrm{ZnO}$ thin film annealed at $400^{\circ} \mathrm{C}, 500^{\circ} \mathrm{C}$ and $600^{\circ} \mathrm{C}$ 


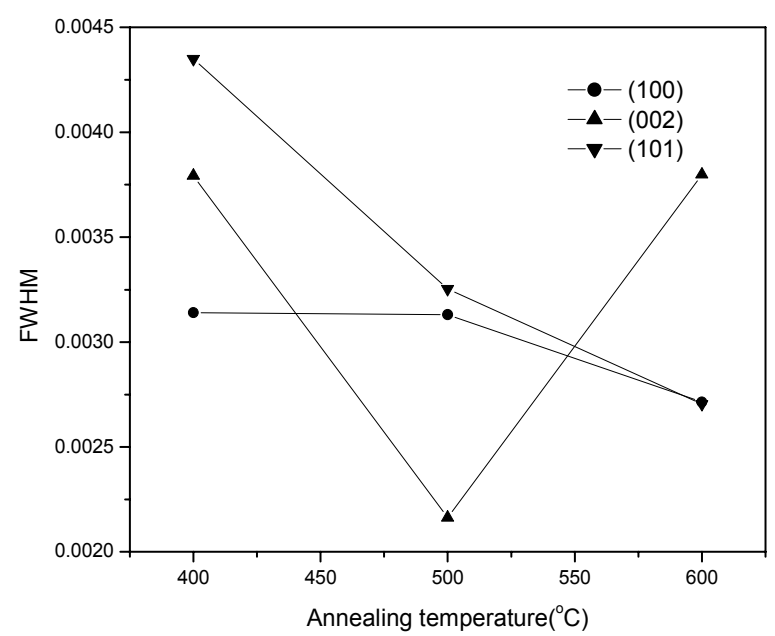

Figure 2. FWHM of $\mathrm{ZnO}$ film as function of annealing temperature

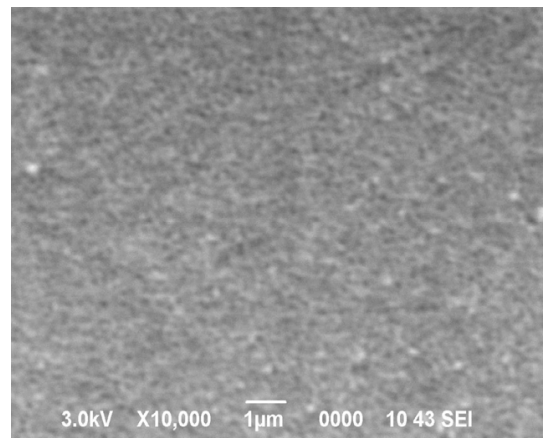

Figure 3. SEM micrograph of $\mathrm{ZnO}$ film annealed at $400^{\circ} \mathrm{C}$

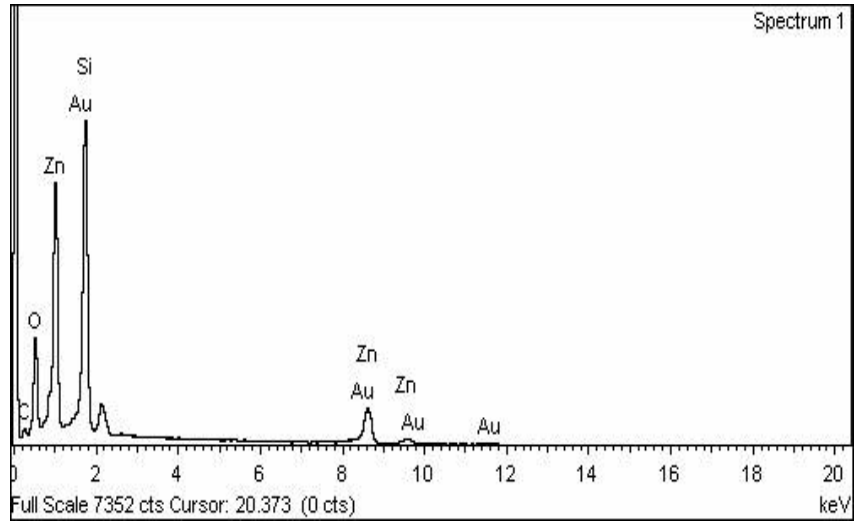

Figure 4. EDS of $\mathrm{ZnO}$ film annealed at $400^{\circ} \mathrm{C}$ 


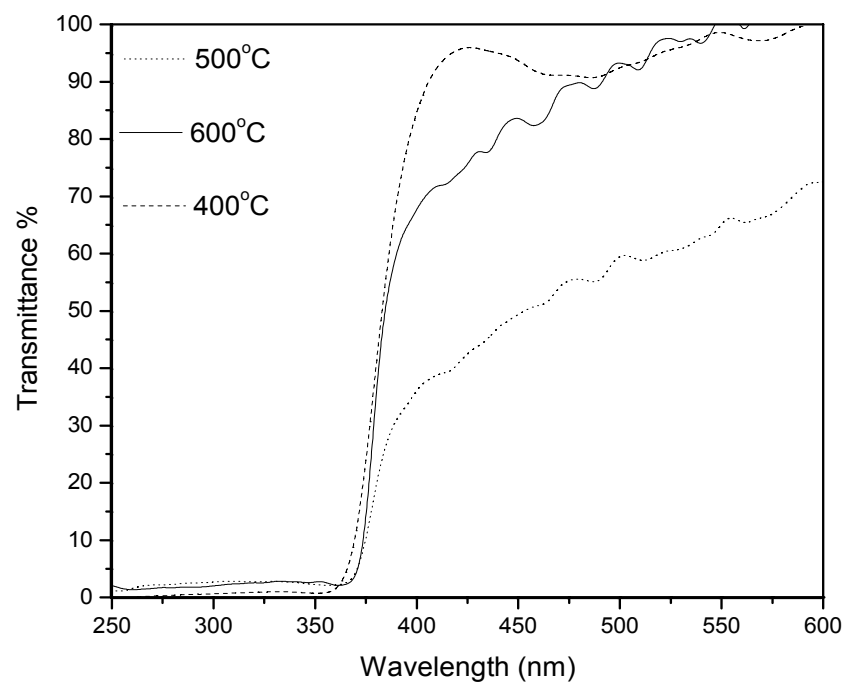

Figure 5.Transmission spectra of $\mathrm{ZnO}$ thin film annealed at $400^{\circ} \mathrm{C}, 500^{\circ} \mathrm{Cand} 600^{\circ} \mathrm{C}$

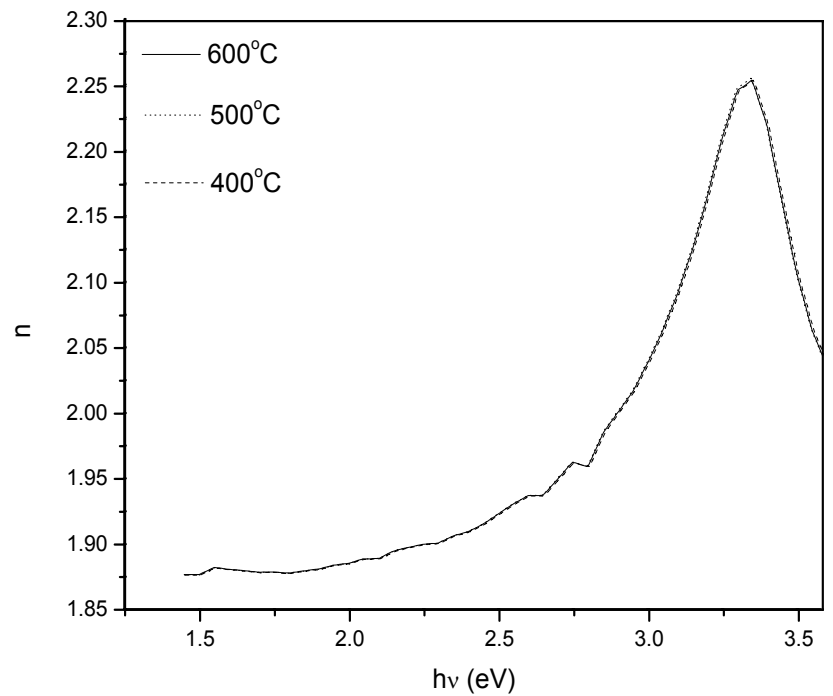

Figure 6. Plot of refractive index $\mathrm{n}$ as a function of Photon energy for $\mathrm{ZnO}$ film at different annealing temperature 


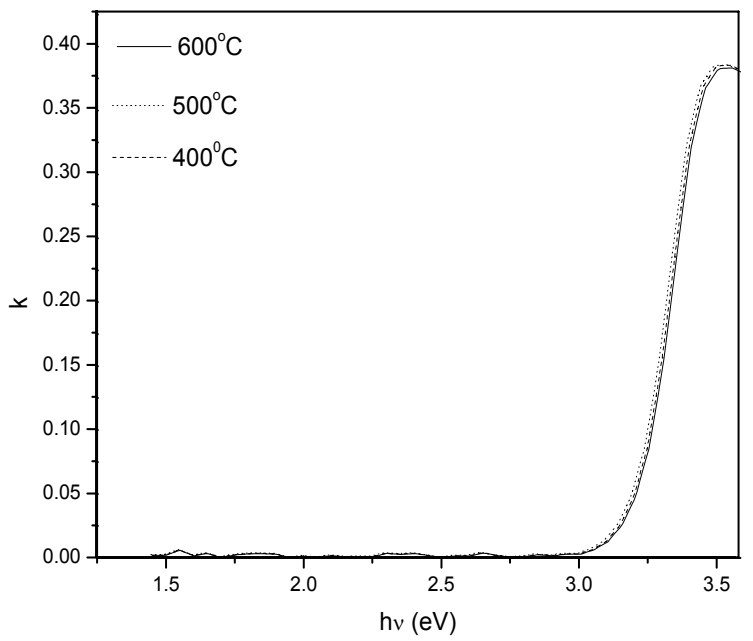

Figure 7. Plot of extinction coefficient $\mathrm{k}$ as a function of Photon energy for $\mathrm{ZnO}$ films at different annealing temperature

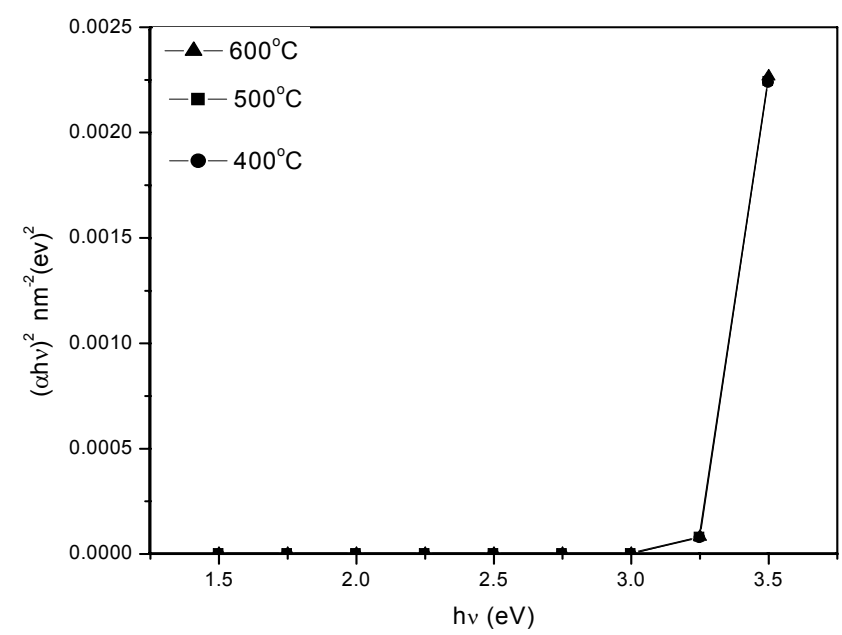

Figure 8. Plot of $(\alpha h v)^{2}$ vs. Photon energy hv for $\mathrm{ZnO}$ films at different annealing temperatures 


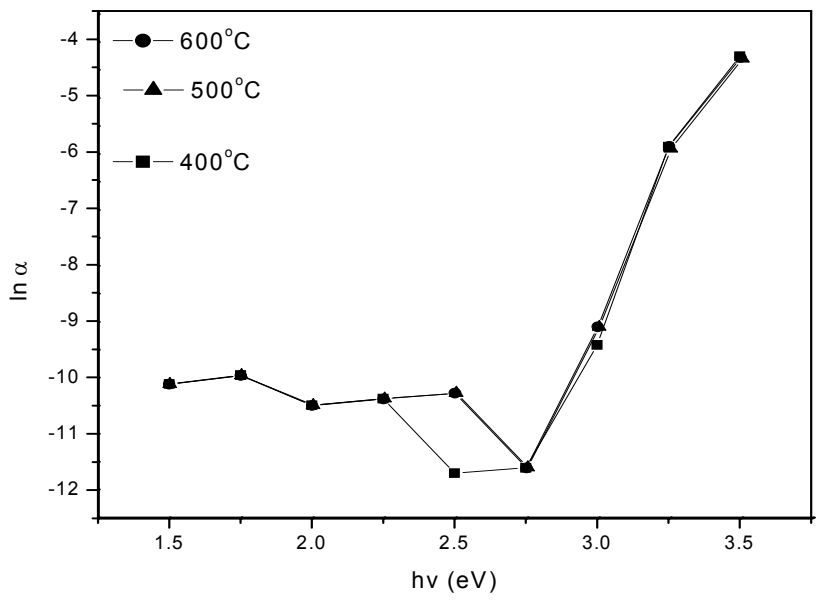

Figure 9. Urbach plot for $\mathrm{ZnO}$ film annealed at $400^{\circ} \mathrm{C}, 500^{\circ} \mathrm{C}$ and $600^{\circ} \mathrm{C}$

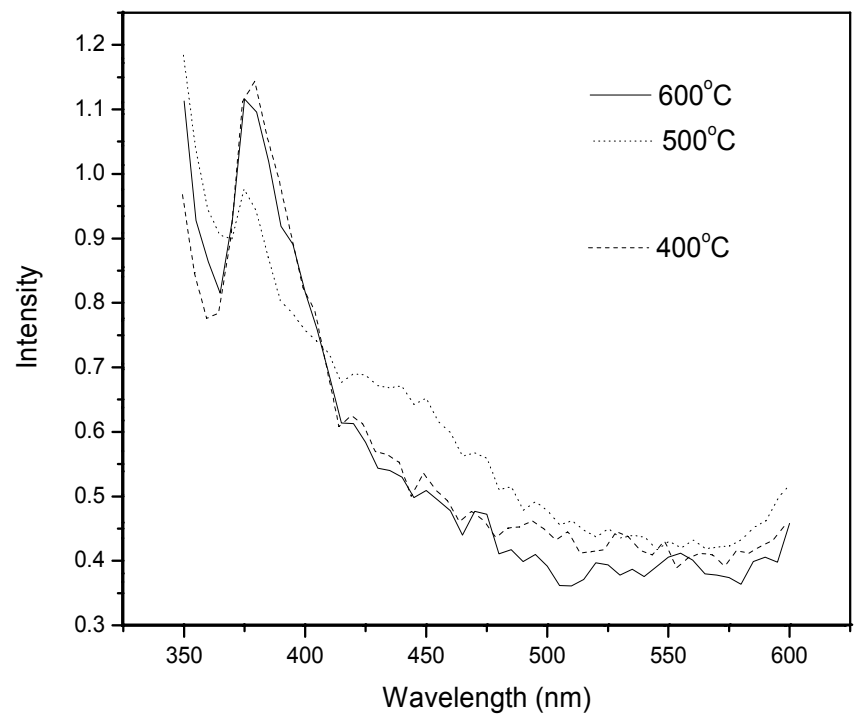

Figure 10. Room temperature Photoluminescence spectrum of $\mathrm{ZnO}$ films annealed at different temperatures 